\title{
Detection of aneuploidies in spontaneous abortions by quantitative fluorescent PCR with short tandem repeat markers: a retrospective study
} E.C.C. Mateo $^{2}$ and A.C.S. Ferreira ${ }^{2}$

${ }^{1}$ Departamento de Genética Molecular, Instituto Hermes Pardini, Vespasiano, MG, Brasil

${ }^{2}$ Pesquisa \& Desenvolvimento, Instituto Hermes Pardini, Vespasiano, MG, Brasil ${ }^{3}$ Core Lab, Instituto Hermes Pardini, Vespasiano, MG, Brasil

Corresponding author: F.K. Marques

E-mail: fabiana.marques@labhpardini.com.br

Genet. Mol. Res. 15 (3): gmr.15038617

Received March 9, 2016

Accepted June 22, 2016

Published September 23, 2016

DOI http://dx.doi.org/10.4238/gmr.15038617

Copyright $(2016$ The Authors. This is an open-access article distributed under the terms of the Creative Commons Attribution ShareAlike (CC BY-SA) 4.0 License.

\begin{abstract}
Approximately $10-15 \%$ of all pregnancies end in spontaneous abortions. Many factors can lead to embryonic loss; however, it has been well established that over $50 \%$ of all miscarriages result from chromosomal abnormalities, primarily aneuploidies (>96\%). Identifying the cause of miscarriage can significantly reduce the psychological stress in women, and enable better genetic counseling for a future pregnancy. Quantitative fluorescent polymerase chain reaction (QF-PCR) has been previously used in the study of chromosomal abnormalities. In this retrospective study, the frequency of aneuploidy in samples of 130 miscarriages undergone by patients
\end{abstract}


(age average: $34.1 \pm 4.6$ years) at our institution was determined by QF-PCR using short tandem repeat markers. The gender of the miscarriage cases was determined by amplifying the amelogenin locus (70 males and 60 females). Seventy-one of these cases (54.6\%) presented aneuploidies such as trisomy, monosomy, triploidy, and double trisomy. Trisomy 22 was the most common aneuploidy (present in 14 cases), followed by trisomy 15 , trisomy 16 , and monosomy X. We also observed monosomy at chromosomes $\mathrm{X}$ and 21 and a case with multiple aneuploidies at chromosomes 16 and 22. The most common aneuploidies associated with miscarriages were detected by QF-PCR; therefore, we concluded that QF-PCR is a rapid and reliable method for the detection of aneuploidy, and can be used as an accessory to the widely used karyotype analysis.

Key words: Spontaneous abortions; Aneuploidy; QF-PCR; STR markers

\section{INTRODUCTION}

Approximately 10-15\% of all pregnancies end in spontaneous abortions (Miller et al., 1980; Quenby et al., 2002). Infections, maternal hormonal imbalances, uterine malformations, immunological disorders, and fetal genetic abnormalities can lead to embryonic loss (Shearer et al., 2011). It is well established that over $50 \%$ of abortions result from chromosomal abnormalities (Menasha et al., 2005; Shearer et al., 2011). Aneuploidy, particularly on chromosomes $13,15,16,18,21,22, \mathrm{X}$, and $\mathrm{Y}$, is the major type of chromosomal abnormality $(>96 \%)$ that leads to miscarriages (Carrera et al., 1996; Jia et al., 2015). Aneuploidy is caused by non-disjunction in meiosis I and meiosis II during gametogenesis, resulting in an abnormal number of chromosomes in the gametes (Weaver et al., 2006). Autosomal trisomy, in particular, is responsible for a large percentage of miscarriages (Kalousek et al., 1993). Studies show that women with one or more miscarriages caused by aneuploidy are at an increased risk of developing fetuses with chromosomal abnormalities in the future (Bianco et al., 2006). Identifying the cause of miscarriage can significantly reduce psychological stress in women who suffer from miscarriages (Nikcevic et al., 1999) and enable better genetic counseling to the couple for a future pregnancy (Carp et al., 2001). Full cytogenetic karyotype is the gold standard technique for the study of products of conception, and is highly recommended even in the case of a first spontaneous abortion (Silvestre et al., 2002), as it allows the evaluation of all chromosomes. However, this technique entails problems such as culture failure, contamination of the sample with maternal cells, high cost, and relatively high time to obtain the result (Bán et al., 2002). Quantitative fluorescent polymerase chain reaction (QF-PCR), which is based on the analysis of microsatellite markers (short tandem repeats, STRs), is a diagnostic tool capable of detecting aneuploidy directly from the genomic DNA isolated from products of conception, without using growing cells (Osborne et al., 2005; Zou et al., 2008; Comas et al., 2010). We have previously used QF-PCR to study spontaneous abortions. It is an interesting alternative to karyotype analysis because of its reliability, sensibility, and lower cost. The aim of this retrospective study was to determine the incidence and types of aneuploidies responsible for miscarriage in patients referred to our institution for the molecular study of conception products by QF-PCR.

Genetics and Molecular Research 15 (3): gmr.15038617 


\section{MATERIAL AND METHODS}

\section{Biological samples}

We carried out a retrospective study of 130 QF-PCR results of miscarriage content performed at Hermes Pardini Institute between 2013 and 2014 by women who underwent spontaneous abortion. Data such as the gestational age at abortion and the reproductive history of the mothers were not included, because majority of the samples were referred to our laboratory with limited clinical data. Ovular remains and embryonic or fetal tissue specimens were analyzed prior to DNA extraction. The material received was previously examined under a microscope to separate a section of the fetal material for the study. Possible contamination of the fetal material by maternal blood was confirmed by analyzing maternal blood samples. All information was obtained from our databank. This retrospective study was conducted using data from anonymous patients; therefore, this study was exempted from the informed consent requirement.

\section{DNA extraction}

DNA was extracted from approximately 1-3 g fetal material using a standard phenolchloroform extraction method (Sambrook et al., 1989). Maternal DNA was extracted using an FTA $^{\mathrm{TM}}$ classic card (GE Healthcare, Little Chalfont, UK). The extracted samples were also subjected to a paternity test using the standard VeriFiler ${ }^{\mathrm{TM}}$ direct PCR amplification kit (Thermo Fisher Scientific, Waltham, MA, USA). When maternal contamination was detected in fetal samples, we attempted to separate the material again; in case of persistent contamination, the fetal sample was excluded from the study. Uncontaminated fetal samples were amplified by QF-PCR using ChromoQuant ${ }^{\circledR}$ QF-PCR and ChromoQuant PLUS ${ }^{\circledR}$ QF-PCR kits (CyberGene, Solna, Sweden), to detect or exclude the presence of aneuploidy on chromosomes 13, 15, 16, $18,21,22, \mathrm{X}$, and $\mathrm{Y}$.

\section{QF-PCR}

QF-PCR is based on the assumption that the amount of specific DNA produced during the exponential phase of PCR is proportional to the quantity of the initial target (Diego-Alvarez et al., 2005). Amplification of the highly polymorphic chromosomespecific STR sequences should, therefore, indicate the high rate of heterozygosity among individuals. In this study, PCR products were detected and quantified by analyzing the peak areas shown by a DNA analyzer using fluorescent primers (Nicolini et al., 2004; Diego-Alvarez et al., 2005). The 12.5- $\mu \mathrm{L}$ PCR mixture was composed of $5 \mu \mathrm{L}$ template DNA (diluted to 1.5-2.0 $\mathrm{ng} / \mu \mathrm{L}$ ) and $7.5 \mu \mathrm{L}$ ChromoQuant mix, comprising a Taq polymerase. We performed five independent multiplex reactions with STR markers for chromosomes 21, X, and $\mathrm{Y}$; chromosomes 13, 18, X, and $\mathrm{Y}$; chromosome 15; chromosome 16; and chromosome 22 (Table 1). The reaction conditions were set as follows: 26 cycles of denaturation at $94^{\circ} \mathrm{C}$ for $30 \mathrm{~s}$, annealing at $57^{\circ} \mathrm{C}$ for $1 \mathrm{~min}$, and extension at $71^{\circ} \mathrm{C}$ for 2 min; and a final extension at $71^{\circ} \mathrm{C}$ for 5 min. Additional markers (ChromoQuant ${ }^{\mathbb{B}} \mathrm{QF}-\mathrm{PCR}$ and ChromoQuant plus ${ }^{\circledR}$ QF-PCR kits; CyberGene AB) were used in case of homozygosity of all markers specific for chromosomes 13, 18, and 21, and the sex chromosomes. The protocol and PCR program were the same as for the other markers. The PCR products

Genetics and Molecular Research 15 (3): gmr.15038617 
$(1 \mu \mathrm{L})$ were mixed with HI-DI formamide $(8.7 \mu \mathrm{L})$ and GeneScan ${ }^{\mathrm{TM}} 500 \mathrm{ROX}^{\circledR}$ size standard $(0.3 \mu \mathrm{L}$; Thermo Fisher Scientific). The products were electrophoresed using the 3730 DNA sequencer by Thermo Fisher Scientific. The amplification products were analyzed and their relative fluorescent intensities were calculated using the Gene marker software (Softgenetics, State College City, PA, USA). The allelic ratio was subsequently determined for each marker. In a normal sample, two doses of an STR marker can be observed as two peaks at a 1:1 ratio. A trisomy sample presents three doses of an STR marker, which is observed either as three peaks at a 1:1:1 ratio (three peaks), or as a pattern of two peaks, at a 2:1 ratio. Triploidy can be detected when the markers studied in all chromosomes show a trisomic pattern of amplification.

Table 1. Short tandem repeat (STR) markers from Chromo Quant ${ }^{\circledR}$ kit used in quantitative fluorescence polymerase chain reaction (QF-PCR) assays.

\begin{tabular}{|c|c|c|}
\hline Marker & Chromosome & Size (bp) \\
\hline AMEL & $\mathrm{Xp} 22.31-\mathrm{Xp} 22.1$ & $\mathrm{X}: 103-108, \mathrm{Y}: 109-114$ \\
\hline D13S797 & $13 \mathrm{q} 33.2$ & $175-250$ \\
\hline D18S391 & $18 \mathrm{p} 11.31$ & $135-185$ \\
\hline D18S976 & $18 \mathrm{p} 11.31$ & $166-201$ \\
\hline D18S819 & $18 \mathrm{q} 11.2$ & $230-275$ \\
\hline XHPRT & $\mathrm{Xq} 26.1$ & $260-304$ \\
\hline D13S742 & $13 q 12.13$ & $230-326$ \\
\hline DXYS218 & $\mathrm{Xp} 22.32 / \mathrm{Yp} 11.3$ & $310-350$ \\
\hline D18S390 & $18 \mathrm{q} 22.3-18 \mathrm{q} 23$ & $315-360$ \\
\hline D18S386 & $18 \mathrm{q} 22.1$ & $330-405$ \\
\hline D13S634 & $13 q 21.33$ & $380-445$ \\
\hline D13S628 & $13 \mathrm{q} 31.1$ & $420-475$ \\
\hline D13S305 & $13 \mathrm{q} 31.3$ & $425-470$ \\
\hline D18S535 & $18 \mathrm{q} 12.3$ & $450-505$ \\
\hline DXS6854 & $\mathrm{Xq} 26.1$ & $91-119$ \\
\hline DXS6803 & $\mathrm{Xq} 21.31$ & 101-139 \\
\hline D21S1409 & $21 \mathrm{q} 21.2$ & $189-219$ \\
\hline SRY & Yp11.31 & $202-207$ \\
\hline $\mathrm{X} 22$ & $\mathrm{Xq} 28 \mathrm{Yq}$ & $190-250$ \\
\hline D21S11 & $21 \mathrm{q} 21.1$ & $224-273$ \\
\hline D21S1246 & $21 \mathrm{q} 22.2$ & $282-336$ \\
\hline D21S1411 & $21 \mathrm{q} 22.3$ & $283-344$ \\
\hline D21S1444 & $21 \mathrm{q} 22.13$ & $300-345$ \\
\hline D21S1435 & $21 \mathrm{q} 21.1$ & $350-410$ \\
\hline DXS6803 & Xq21.31 & 101-139 \\
\hline DXS8377 & $\mathrm{Xq} 28$ & $198-280$ \\
\hline DXS6809 & Xq21.33 & $230-285$ \\
\hline G10_STS47 & Yq11.222 & $338-343$ \\
\hline TAF9B & 3p24.2, Xp13.1-q21.1 & $205(\mathrm{chr} 3), 210(\mathrm{chrX})$ \\
\hline D15S195 & $15 \mathrm{q} 21$ & $100-160$ \\
\hline D15S652 & $15 \mathrm{q} 26$ & $279-321$ \\
\hline D15S659 & $15 \mathrm{q} 15$ & $167-215$ \\
\hline D15S822 & $15 \mathrm{q} 12$ & 301-369 \\
\hline D16S539 & $16 \mathrm{q} 24.1$ & $266-314$ \\
\hline D16S748 & $16 \mathrm{p} 12.2$ & $181-214$ \\
\hline D16S2616 & $16 \mathrm{p} 13.2$ & $109-142$ \\
\hline D16S2621 & $16 \mathrm{q} 23$ & $232-271$ \\
\hline D22S532 & $22 \mathrm{q} 13.31$ & $389-417$ \\
\hline D22S686 & $22 \mathrm{q} 11.2$ & $344-390$ \\
\hline D22S689 & $22 \mathrm{q} 12.1$ & 194-234 \\
\hline $\mathrm{D} 22 \mathrm{~S} 1045$ & $22 \mathrm{q} 13.1$ & $137-164$ \\
\hline
\end{tabular}




\section{RESULTS}

A total of 130 [70 (53.8\%) males and 60 (46.2\%) females; average age: $34.1 \pm 4.6$ years] spontaneous abortion tissue samples were analyzed by QF-PCR. The gender of all samples was identified by amplifying the amelogenin locus. The X and Y PCR products were amplified at a normal 1:1 ratio in all male samples, whereas X-specific PCR products were amplified at a 1:1 ratio in female samples. The amplification products of 71 of the 130 cases $(54.6 \%)$ presented aneuploidies such as trisomy, monosomy, triploidy, and double trisomy (Table 2). Among these, trisomy 22 (14 cases), trisomy 15, trisomy 16, and monosomy X were commonly observed. Trisomy samples presented triallelic patterns with a 1:1:1 ratio between the three peaks, or diallelic patterns with a 2:1 ratio between the two peaks (Figure 1). We also observed monosomy on chromosomes $\mathrm{X}$ and 21 . Chromosome $\mathrm{X}$ monosomy was characterized by the presence of a single QF-PCR product for all X chromosome markers (only one peak for all markers) and by the absence of the Y-specific amelogenin locus (Figure 2). Triploidy was observed in $11.3 \%(8 / 71)$ of the samples with aneuploidies. Trisomy patterns (triallelic and diallelic) were observed for all markers (Figure 3). One case of multiple aneuploidies, wherein the patient presented double trisomy of chromosomes 16 and 22, was identified.

Table 2. Incidence and types of aneuploidies in spontaneous miscarriages using quantitative fluorescent polymerase chain reaction (QF-PCR).

\begin{tabular}{l|c}
\hline Aneuploidies & Number of cases $(\%)$ \\
\hline Trisomy 22 & $14(19.7 \%)$ \\
\hline Trisomy 15 & $10(14.1 \%)$ \\
\hline Trisomy 16 & $10(14.1 \%)$ \\
\hline Monosomy X & $10(14.1 \%)$ \\
\hline Triploidy & $8(11.3 \%)$ \\
\hline Trisomy 21 & $7(9.8 \%)$ \\
\hline Trisomy 13 & $6(8.5 \%)$ \\
\hline Trisomy 18 & $4(5.6 \%)$ \\
\hline Double trisomy & $1(1.4 \%)$ \\
\hline Monosomy 21 & $1(1.4 \%)$ \\
\hline Total & $71(100 \%)$ \\
\hline
\end{tabular}


Figure 1. QF-PCR amplification of a miscarriage product resulting from trisomy 22. Amplification of the D22S532 marker evidenced a trisomic diallelic pattern (2:1), whereas that of the D22S686, D22S689, and D22S1045 markers presented a trisomic triallelic pattern (1:1:1) of aneuploidy.

Genetics and Molecular Research 15 (3): gmr.15038617 

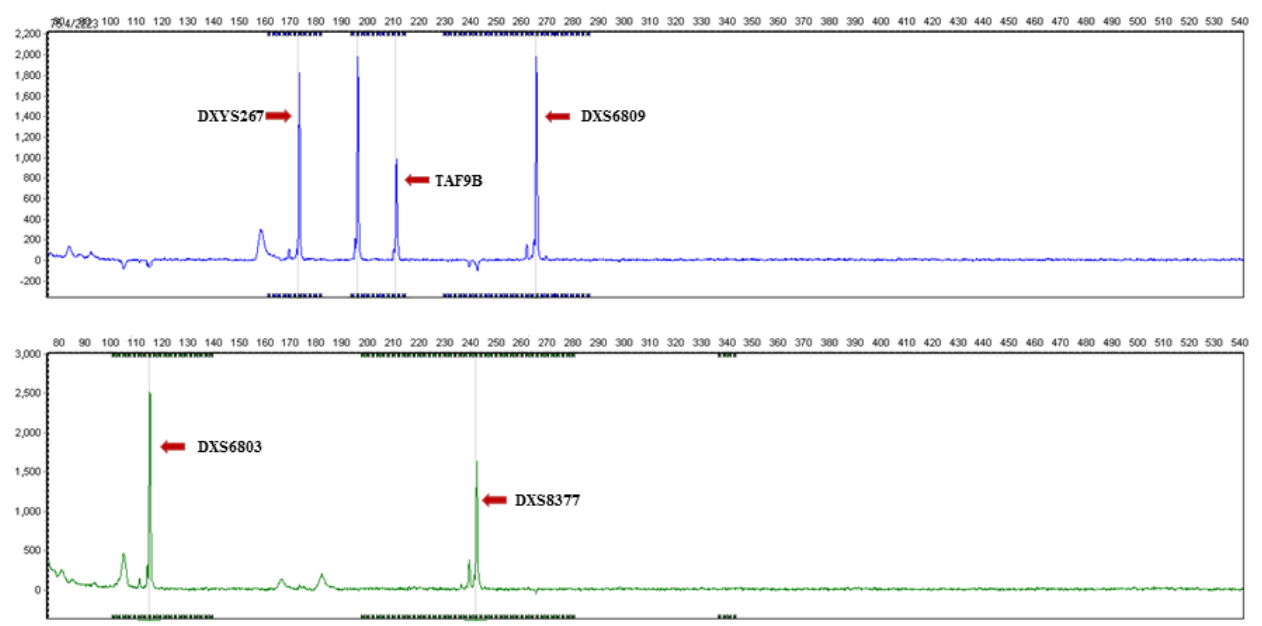

Figure 2. Electropherogram of the amplification products of a monosomy X-carrying miscarriage sample. Amplification of the DXYS267 marker resulted in one peak corresponding to the X chromosome. Only one peak was observed for the X-specific STR markers DXS6809, DXS6803, and DXS8377. TAF9B has a pseudogene on chromosome 3, evidenced by one peak representing two chromosomes 3 (196-198 bp) and one peak corresponding to the X chromosome (210-212 bp). TAF9B presents a 1:1 ratio in a normal XX sample; however, because of the presence of a single X-chromosome, we observed a 2:1 ratio between the two peaks in TAF9B.
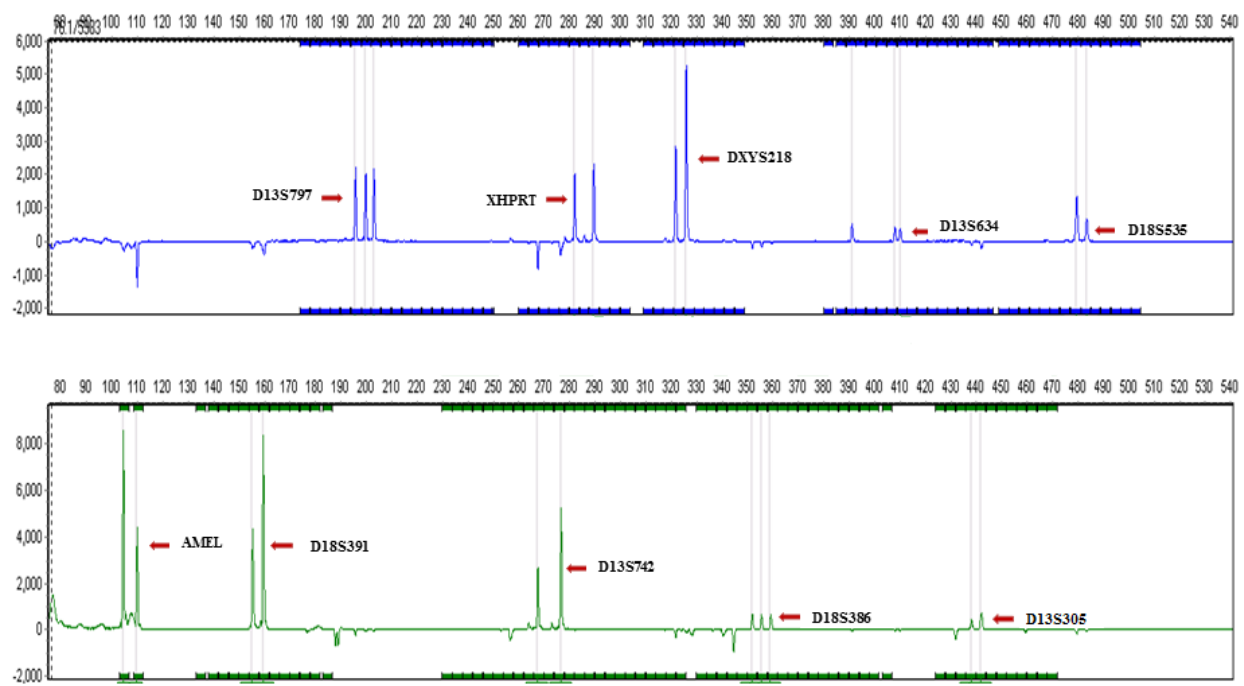

Figure 3. Electropherogram of the amplification products from a triploid miscarriage sample showing 2:1 peaks for markers DXYS218, D18S535, AMEL, D18S391, D13S742, and D13S305 and 1:1:1 peaks for markers D13S797, D13S634 and D18S386. XHPRT marker presented a disomic pattern (1:1).

\section{DISCUSSION}

Chromosomal analysis of the products of conception could play a useful role in determining the causes of miscarriage, and in estimating the risk of recurrence in future 
pregnancies. More than $50 \%$ of spontaneous abortions are known to carry chromosomal aneuploidies; in fact, researchers have reported a rate of aneuploidy ranging from 23 to $61 \%$ (Lomax et al., 2000; Menten et al., 2009). In this retrospective study, QF-PCR analysis of 130 miscarriage samples revealed the presence of aneuploidies in $54.6 \%$ of the cases. Shearer et al. (2011) reported that approximately 1613 of 3361 (48\%) karyotype samples presented numerical chromosome abnormalities, whereas Zou et al. (2008) reported an aneuploidy frequency of $36.1 \%$ in 61 miscarriage samples, using QF-PCR. Our study revealed that the major chromosomal abnormalities related to spontaneous abortions included trisomy, monosomy X, and triploidy. In particular, autosomal trisomy was responsible for a large number of abortions. Trisomy 22 was the most frequently identified aneuploidy, followed by trisomy 15 and trisomy 16. Alternately, Menasha et al. (2005) identified trisomy 16, 22, and 21 as the most common aneuploidies via karyotype analysis. Jia et al. (2015), however, identified trisomy 16, trisomy 22 , and monosomy $\mathrm{X}$ as the most frequent aneuploidies, via fluorescence in situ hybridization (FISH). Although trisomies in all chromosomes are implicated in spontaneous abortions, the most common trisomies, involving chromosomes 14, 15, 16, and 22 (Stephenson et al., 2002; Menasha et al., 2005), have been identified as major causes of early spontaneous abortions. Anomalies on chromosomes 13,18,21, and the sex chromosome are more common in late miscarriages (Menasha et al., 2005). Our study was limited by the lack of availability of information regarding the gestational age.

QF-PCR allowed the identification of triploidy in $11.3 \%$ of the samples. DiegoAlvarez et al. (2005) identified triploidy in $12.5 \%$ of their study population using QF-PCR. Jenderny (2014) detected triploidy in $12 \%$ of all studied abortions by cytogenetic analysis. Triploidy is common in early pregnancy (1-3\% of all clinically recognized pregnancies); however, approximately $99 \%$ of the fetuses are lost before the third trimester (Jenderny, 2014). The incidence of fetuses developing with chromosomal abnormalities is known to reduce as the pregnancy progresses; however, the exact reason for the frequent occurrence of certain types of aneuploidies remains unknown (Diego-Alvarez et al., 2005). Embryos that are carriers of these aneuploidies can successfully achieve implantation and initiate the pregnancy, but cannot develop until birth. Some abnormalities, such as autosomal monosomy and several types of aneuploidies, are very rare because of their lethality. Embryos with these defects are managed by the natural selection mechanism, which operates via the interruption and degeneration of abnormal embryos (Diego-Alvarez et al., 2005). We identified one case (1.4\%) of multiple aneuploidy, a double trisomy involving chromosomes 16 and 22. Double trisomy/ aneuploidy is observed in 0.21-2.8\% of abortions (Reddy, 1997; Diego-Alvarez et al., 2005; Micale et al., 2010). Subramaniyam et al. (2014) reported that chromosomes 21, 16, X, 22, 18,13 , and 15 were chiefly involved in double trisomy, in the decreasing order of frequency. Double aneuploidies are also associated with advanced maternal age and miscarriage at a very early gestational age (Reddy, 1997). Our case of double trisomy cannot be related to the maternal age, as the mother was 36 years old. Moreover, one case with monosomy 21 was identified in this study. Monosomy 21 was the most common autosomal monosomy observed in a study published by Shearer et al. (2011). Loss of a chromosome may be lethal because of the haploinsufficiency of essential genes to development. Chromosome X monosomy is the only monosomy compatible with life. QF-PCR facilitated the detection of major aneuploidies associated with spontaneous abortions. This highly accurate and rapid method can be used to detect numerical chromosomal abnormalities, and is economical compared to karyotype analysis. This technique allows the simultaneous analysis of various chromosomes and a 
large number of samples. However, this method has certain limitations: it does not offer a correct diagnosis for mosaicism, small deletions, duplications, and translocations. QF-PCR is a rapid and reliable method for the detection of aneuploidy in spontaneous abortions and can be considered as an accessory to karyotype analysis.

\section{Conflicts of interest}

The authors declare no conflict of interest.

\section{ACKNOWLEDGMENTS}

The authors would like to thank the Hermes Pardini Institute for the technical and financial support provided for this study.

\section{REFERENCES}

Bán Z, Nagy B, Papp C, Tóth-Pál E, et al. (2002). Rapid diagnosis of triploidy of maternal origin using fluorescent PCR and DNA fragment analysis in the third trimester of pregnancy. Prenat. Diagn. 22: 984-987. http://dx.doi. org $/ 10.1002 /$ pd. 453

Bianco K, Caughey AB, Shaffer BL, Davis R, et al. (2006). History of miscarriage and increased incidence of fetal aneuploidy in subsequent pregnancy. Obstet. Gynecol. 107: 1098-1102. http://dx.doi.org/10.1097/01. AOG.0000215560.86673.22

Carp H, Toder V, Aviram A, Daniely M, et al. (2001). Karyotype of the abortus in recurrent miscarriage. Fertil. Steril. 75: 678-682.http://dx.doi.org/10.1016/S0015-0282(00)01801-X

Carrera M, Ribas I, Torrents M, Méndez B, et al. (1996). Abortos espontâneos de repetición y anomalias cromossômicas numéricas: es el diagnóstico preimplantacional uma alternativa diagnóstica? Prog. Diagn. Prenat. 8: 342-347.

Comas C, Echevarria M, Carrera M and Serra B (2010). Rapid aneuploidy testing versus traditional karyotyping in amniocentesis for certain referral indications. J. Matern. Fetal Neonatal Med. 23: 949-955. http://dx.doi. org/10.3109/14767050903334893

Diego-Alvarez D, Garcia-Hoyos M, Trujillo MJ, Gonzalez-Gonzalez C, et al. (2005). Application of quantitative fluorescent PCR with short tandem repeat markers to the study of aneuploidies in spontaneous miscarriages. Hum. Reprod. 20: 1235-1243. http://dx.doi.org/10.1093/humrep/deh781

Jenderny J (2014). Chromosome aberrations in a large series of spontaneous miscarriages in the German population and review of the literature. Mol. Cytogenet. 7: 38. http://dx.doi.org/10.1186/1755-8166-7-38

Jia CW, Wang L, Lan YL, Song R, et al. (2015). Aneuploidy in early miscarriage and its related factors. Chin. Med. J. 128: 2772-2776. http://dx.doi.org/10.4103/0366-6999.167352

Kalousek DK, Pantzar T, Tsai M and Paradice B (1993). Early spontaneous abortion: morphologic and karyotypic findings in 3,912 cases. Birth Defects Orig. Artic. Ser. 29: 53-61.

Lomax B, Tang S, Separovic E, Phillips D, et al. (2000). Comparative genomic hybridization in combination with flow cytometry improves results of cytogenetic analysis of spontaneous abortions. Am. J. Hum. Genet. 66: 1516-1521. http://dx.doi.org/10.1086/302878

Menasha J, Levy B, Hirschhorn K and Kardon NB (2005). Incidence and spectrum of chromosome abnormalities in spontaneous abortions: new insights from a 12-year study. Genet. Med. 7: 251-263. http://dx.doi.org/10.1097/01. GIM.0000160075.96707.04

Menten B, Swerts K, Delle Chiaie B, Janssens S, et al. (2009). Array comparative genomic hybridization and flow cytometry analysis of spontaneous abortions and mors in utero samples. BMC Med. Genet. 10: 89. http://dx.doi. org/10.1186/1471-2350-10-89

Micale M, Insko J, Ebrahim SA, Adeyinka A, et al. (2010). Double trisomy revisited - a multicenter experience. Prenat. Diagn. 30: 173-176. http://dx.doi.org/10.1002/pd.2429

Miller JF, Williamson E, Glue J, Gordon YB, et al. (1980). Fetal loss after implantation. A prospective study. Lancet 2: 554-556. http://dx.doi.org/10.1016/S0140-6736(80)91991-1

Genetics and Molecular Research 15 (3): gmr.15038617 
Nicolini U, Lalatta F, Natacci F, Curcio C, et al. (2004). The introduction of QF-PCR in prenatal diagnosis of fetal aneuploidies: time for reconsideration. Hum. Reprod. Update 10: 541-548. http://dx.doi.org/10.1093/humupd/ $\underline{\mathrm{dmh} 046}$

Nikcevic AV, Tunkel SA, Kuczmierczyk AR and Nicolaides KH (1999). Investigation of the cause of miscarriage and its influence on women's psychological distress. Br. J. Obstet. Gynaecol. 106: 808-813. http://dx.doi. org/10.1111/j.1471-0528.1999.tb08402.x

Osborne EC, Trounson AO and Cram DS (2005). A QF-PCR system to detect chromosome 13 aneuploidy from as few as ten cells. Am. J. Med. Genet. A. 134A: 33-38. http://dx.doi.org/10.1002/ajmg.a.30428

Quenby S, Vince G, Farquharson R and Aplin J (2002). Recurrent miscarriage: a defect in nature's quality control? Hum. Reprod. 17: 1959-1963. http://dx.doi.org/10.1093/humrep/17.8.1959

Reddy KS (1997). Double trisomy in spontaneous abortions. Hum. Genet. 101: 339-345. http://dx.doi.org/10.1007/ $\underline{\mathrm{s} 004390050638}$

Sambrook J, Fritschi EF and Maniatis T (1989). Molecular cloning: a laboratory manual. 2nd edn. Cold Spring Harbor Laboratory Press, New York.

Shearer BM, Thorland EC, Carlson AW, Jalal SM, et al. (2011). Reflex fluorescent in situ hybridization testing for unsuccessful product of conception cultures: a retrospective analysis of 5555 samples attempted by conventional cytogenetics and fluorescent in situ hybridization. Genet. Med. 13: 545-552. http://dx.doi.org/10.1097/ GIM.0b013e31820c685b

Silvestre E, Cusí V, Antich J and Caballín MR (2002). Protocolo para el estúdio citogenético de los abortos espontâneos. Program Diagnosis Prenatal 14: 146-151.

Stephenson MD, Awartani KA and Robinson WP (2002). Cytogenetic analysis of miscarriages from couples with recurrent miscarriage: a case-control study. Hum. Reprod. 17: 446-451.http://dx.doi.org/10.1093/humrep/17.2.446

Subramaniyam S, Pulijaal VR and Mathew S (2014). Double and multiple chromosomal aneuploidies in spontaneous abortions: A single institutional experience. J. Hum. Reprod. Sci. 7: 262-268. http://dx.doi.org/10.4103/0974$\underline{1208.147494}$

Weaver BA, Silk AD and Cleveland DW (2006). Cell biology: nondisjunction, aneuploidy and tetraploidy. Nature 442: E9-E10, discussion E10. http://dx.doi.org/10.1038/nature05139

Zou G, Zhang J, Li XW, He L, et al. (2008). Quantitative fluorescent polymerase chain reaction to detect chromosomal anomalies in spontaneous abortion. Int. J. Gynaecol. Obstet. 103: 237-240. http://dx.doi.org/10.1016/j. iigo.2008.07.014

Genetics and Molecular Research 15 (3): gmr.15038617 